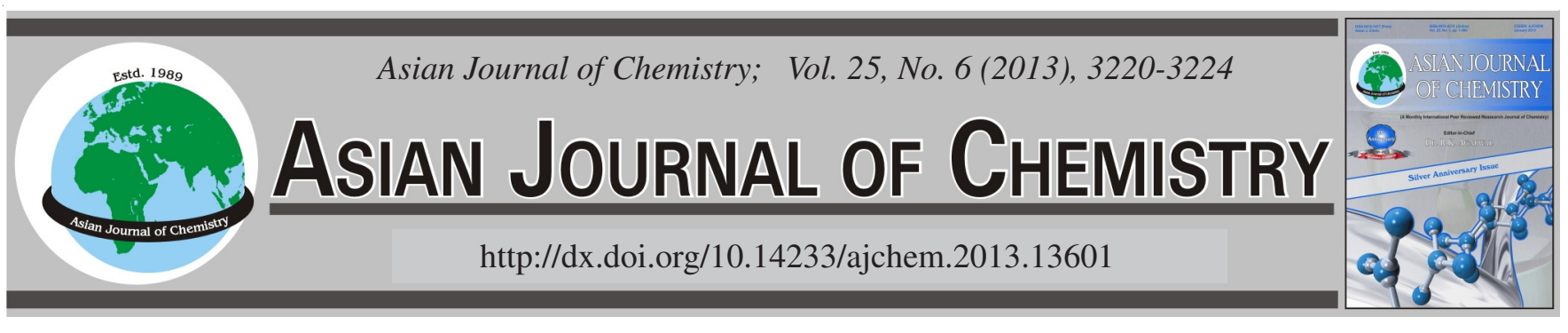

\title{
Printing of Wool and Cotton Fabrics with Natural Dyes
}

\author{
Muhammed Ibrahim BahtiYARI ${ }^{1, *}$, HÜSEYIN BenLI $^{2}$ and ArZu YAVAS ${ }^{3}$
}

${ }^{1}$ Textile Engineering Department, Erciyes University, Kayseri, Turkey

${ }^{2}$ Mustafa Çikrikçioglu Vocational School, Erciyes University, Kayseri, Turkey

${ }^{3}$ Textile Engineering Department, Pamukkale University, Denizli, Turkey

*Corresponding author: E-mail: bahtiyari@erciyes.edu.tr

(Received: 15 February 2012;

Accepted: 14 December 2012)

AJC-12552

\begin{abstract}
Natural dyes are the heritage of the history to human being. Although they were used for the colouration of goods from the ancient time, it is not common to use natural dyes commercially now. But at least in some special goods it is saving its popularities too. On the other hand, it can be foreseen that the demand on the ecological, natural and organic products in all consumable articles will make natural dyes popular again. Owing to this, it is important to continue the studies on the usability of natural dyes in textile colouration techniques. This study is focused on the printing of natural dyes differently on dyeing with natural dyes. For this aim four different natural sources were used. For the printing process, pigment printing was selected and the printing was managed on wool and cotton fabrics without use of any mordants. The colour values and the fastnesses of prints were evaluated. It was observed that the natural dyes can be used in pigment printing processes and different colour values with different fastnesses could be observed.
\end{abstract}

Key Words: Natural dyes, Pigment printing, Wool, Cotton, Fastnesses.

\section{INTRODUCTION}

Natural dyes are pigments derived from mineral, animal or plant sources ${ }^{1}$. They are known since pre-historic times for their use in colouring of food substrate, leather as well as natural fibers like wool, silk and cotton ${ }^{2,3}$. The plants provide a vast source of natural dyes which can be obtained from many parts of the plant e.g., leaves, fruits, seeds, flowers, barks and roots ${ }^{4}$. Most of the natural dyes have no substantivity on textile fibers so need to use mordanting agents. The metallic salts as mordanting agent create the bridging link between the dye molecules and the fiber by forming coordinating complexes ${ }^{2}$.

There is an increasing interest on the use of natural dyes in textile processes. This is a result of the stringent environmental standards imposed by many countries in a response to the toxic and allergic reactions associated with synthetic dyes ${ }^{5}$. Natural dyes are friendlier to the environment than synthetic dyes and can exhibit better biodegradability and generally have a higher compatibility with the environment ${ }^{6}$. So despite their inferior fastness, natural dyes are more acceptable to environmentally conscious people ${ }^{5}$. Although dyeing with natural dyes has widespread in scientific researches, papers on the printing via natural dyes is limited. Rekabya et al. ${ }^{1}$ were used alkanet and rhubarban; Agarwal et al. ${ }^{7}$ were used marigold (Tagetes erecta Linn.) petals as natural dyes in printing of fabrics.
In this study madder, buckthorn, walnut bark and indigo were used as natural dyes during pigment printing of cotton and wool fabrics.

Pigment printing is not only the oldest but also the easiest printing method as far as simplicity of application is concerned $^{8}$. In pigment printing, insoluble pigments, which have no affinity for the fiber, are fixed on to the textile with binding agents. Pigment printing is the most economical printing process and can be applied to all substrates ${ }^{9}$ addition to them it is a simple technical process, results in good light fastness, however, wash fastness is limited ${ }^{10}$ and the handle of the printed goods is often unduly hard ${ }^{9}$.

\section{EXPERIMENTAL}

In the study, wool and cotton fabrics weighing $110 \mathrm{~g} / \mathrm{m}^{2}$ and $120 \mathrm{~g} / \mathrm{m}^{2}$, respectively were used. Both fabrics were pretreated and ready for printing processes. Their whiteness degrees were 47 and 83 Stensby respectively.

For printing of wool and cotton fabrics, the pigment printing process was selected as a model and the natural sources' extracts were used directly as dyestuff in printing paste as shown in Table-1.

Fabrics were printed with $4 \mathrm{~m} / \mathrm{min}$ at 7 pres on a laboratory-type printing machine (ATAÇ trade mark). The doctor knife of $12 \mathrm{~mm}$ in diameter was used two times. Then, printed 
TABLE-1

PRINTING PASTE RECIPE

\begin{tabular}{lc}
\hline \multicolumn{2}{c}{ Printing paste* } \\
\hline Thickener (Tubivis VP 681, CHT) & $4 \mathrm{~g}$ \\
\hline Binder (Helizarin Binder ET 95 BASF) & $15 \mathrm{~g}$ \\
Extract & $81 \mathrm{~g}$ \\
\hline Total & $100 \mathrm{~g}$ \\
\hline
\end{tabular}

fabrics were dried in a laboratory type drying machine at $100{ }^{\circ} \mathrm{C}$ for $4 \mathrm{~min}$ and cured at $150{ }^{\circ} \mathrm{C}$ for $5 \mathrm{~min}$.

Walnut bark extract: Walnut, is one of the oldest cultivated fruits in the world, belongs to the Juglandaceae family, juglans variety Juglans regia L. ${ }^{11}$.

The walnuts' fresh green barks were collected and dried in a shadow then these barks were grinded. From these grinded barks $20 \mathrm{~g}$ were taken into extraction period. Afterwards, from the obtained aqueous solution, $200 \mathrm{~mL}$ concentrate dye solution was prepared by evaporation of water (Fig. 1).

Madder and Buckthorn extract: Madder plant (Rubia tinctorum L.) is an important dye plant and is known as Turkish red. It contains mainly alizarin additionally rubiadine and purpurine are present too but in less extent and in the roots of plant. The amount of dyestuff in the plant changes according to the season ${ }^{12}$. Buckthorn dye plant has a very important place in natural dyestuff sources and it is an old Turkish dyestuff source $^{13}$.

The madder and buckthorn were directly purchased in powder phase and $20 \mathrm{~g}$ of these powders were processed in extraction cycle separately. In the extraction equipment the base of dye was extracted by water. Afterwards, from the obtained aqueous solutions, $200 \mathrm{~mL}$ concentrate dye solution was prepared by evaporation of water for each dye extract.

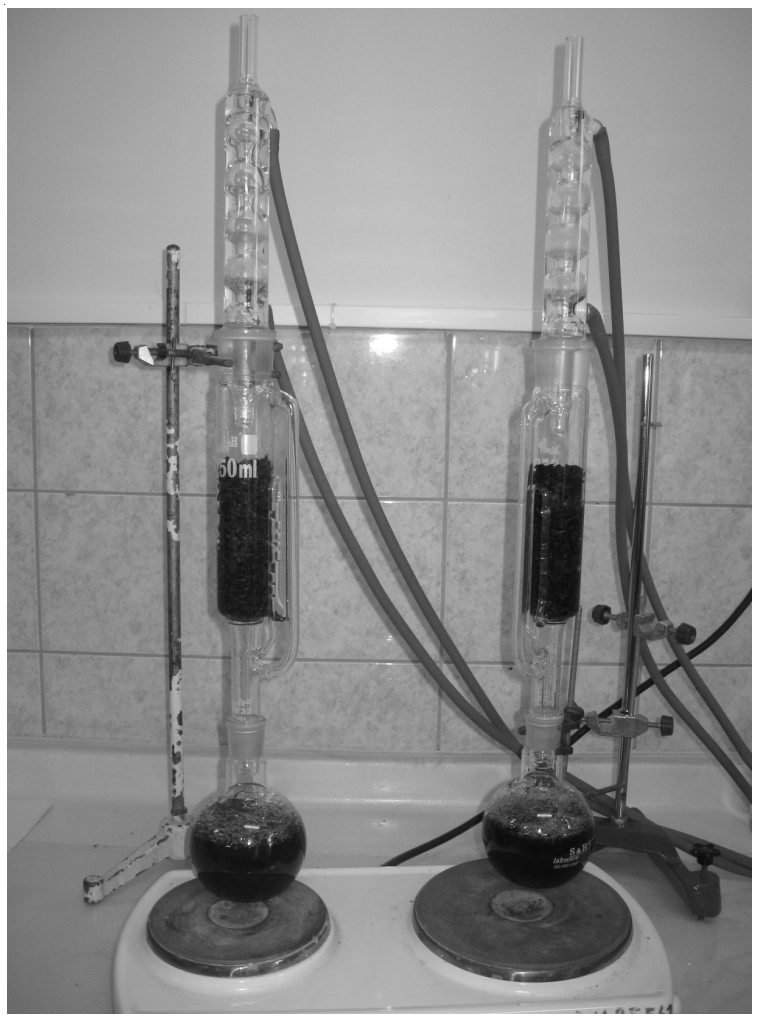

Fig. 1. Extraction equipment used
Indigo extract: Indigo provided the most common source of blue pigment and so a blue to mauve colour called indigotin. It is still in use today too, but now almost all of them are produced synthetically ${ }^{14,15}$. Natural indigo can be derived from a wide range of tropical, sub-tropical and temperate plants from many different species, genera and families. In tropical and sub-tropical areas, the plants most widely used for indigo production were Indigofera spp., of which there are over 350 species. Indigo is not synthesized directly by the plant; it is a product derived from indole glucoside precursors, which are secondary metabolites ${ }^{14}$.

In the study natural indigo extract for printing was prepared dispersing $5 \mathrm{~g}$ indigo powder directly in $200 \mathrm{~mL}$ water. As known for indigo dyeing and printing processes the indigo, which is a kind of vat dye, is firstly reduced to ensure the solubility and after dyeing or printing of reduced indigo, the oxidation is managed to complete dyeing or printing process. But here in the study the natural indigo was directly used in pigment printing process via binders to ensure fixation of dye without any reduction/oxidation process.

For the evaluation of the obtained results; the colour values of printed samples were determined firstly. For this aim CIE $L^{*} a^{*} b *$ values and colour efficiencies (K/S) of printed goods were collected by Minolta $3600 \mathrm{~d}$ spectrophotometer (D 65/ $10^{\circ}$ ). Moreover, to show the prints the photographs of the prints were taken too.

The other important parameters for the examination of the printing efficiency are fastnesses. Owing to this the printed samples washing (ISO 105-C01), rubbing (ISO 105-X12), perspiration (ISO 105-E04) and light fastnesses (ISO 105-B02) of samples were assessed too.

\section{RESULTS AND DISCUSSION}

In this study it was aimed to show that with the use of natural dyestuffs, printing can be managed. Addition to this it was planned to show without mordants a printing process with natural dyes can be carried out too. Owing to this, pigment printing process in which binders were of great importance to fix dyestuffs on fabric was selected.

Colour values and efficiencies of prints: During printing process, indigo was used to provide blue colours, madder for orange-red, Buckthorn for yellow and walnut barks for brown colours. Generally it is assumed that the colour will change according to the textile material and printing process. But in natural dyes this expectation is somewhat high and especially in the dyeing processes the effect of mordant type is of great importance for the shade of the colours ${ }^{2}$ too. During the printing processes in the study as mentioned in Table- 1 no mordant was used. So the colour shade in prints is only related with the natural dye extract, binder and fiber type.

Table- 2 showed that in cotton printing there is an opportunity to use natural dyestuffs in printing of cotton. The use of indigo has also a colouring effect but its shade is too much light and $\mathrm{K} / \mathrm{S}$ value is also low too. The reason of this is thought as directly related with the concentration of indigo solution. As thought above $5 \mathrm{~g}$ indigo was dispersed in $200 \mathrm{~mL}$ and from this solution, $81 \mathrm{~g}$ was taken as an extract in printing paste. So it is believed that like light blue colours, with the 
change of indigo concentration one can reach darker shades and higher colour efficiencies. But for the other tested natural dye based prints, higher colour efficiencies were obtained for cotton (Fig. 2).

\begin{tabular}{lcccc}
\multicolumn{5}{c}{ TABLE-2 } \\
\multicolumn{5}{c}{$\mathrm{L}^{*} \mathrm{a}^{*} \mathrm{~b}^{*}$ VALUES OF PRINTED COTTON } \\
\hline & Indigo & Walnut bark & Madder & Buckthorn \\
\hline $\mathrm{L}^{*}$ & 88.93 & 53.74 & 76.32 & 82.19 \\
$\mathrm{a}^{*}$ & -2.2 & 8.78 & 7.55 & 2.18 \\
$\mathrm{~b}^{*}$ & 5.57 & 25.86 & 29.45 & 28.94 \\
Chroma $\left(\mathrm{C}^{*}\right)$ & 5.99 & 27.31 & 30.41 & 29.03 \\
Hue angle $\left(\mathrm{h}^{\circ}\right)$ & 111.52 & 71.24 & 75.62 & 85.69 \\
\hline
\end{tabular}

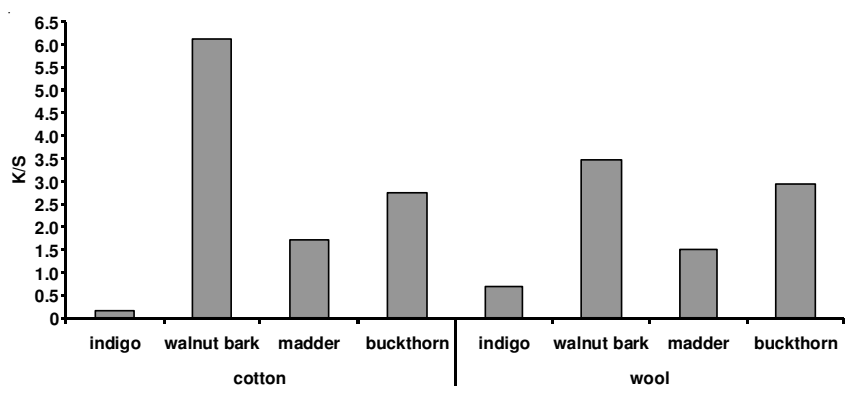

Fig. 2. Colour efficiencies of printed fabrics

This is especially evident in walnut barks based prints. The K/S value was nearly 6.14 in walnut bark printing. As expected in walnut bark based printing, brown colours were obtained. As known the $\mathrm{L}^{*}$ value represents the lightness of the colour $\left(\mathrm{L}^{*}, \mathrm{~L}^{*}=0\right.$ yields black and $\mathrm{L}^{*}=100$ indicates white). In walnut bark printing the obtained colours $\mathrm{L}^{*}$ value was comparatively low, which means the lightness of colour is low. Addition to this, from the Table- 2 the colour is in redyellow area $\left(a^{*}=8.78\right.$ and $\left.b^{*}=25.86\right)$ with a hue value of 71.24. When the all colour values examined for walnut bark printing it can be told that a brown colour can be obtained with this kind of natural dye (Fig. 3).
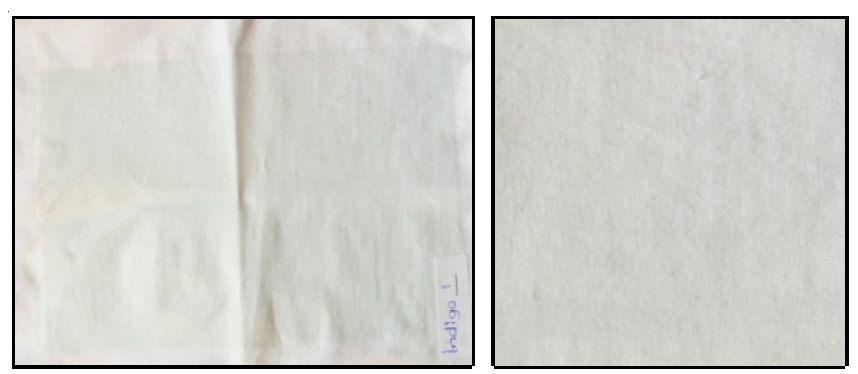

Indigo
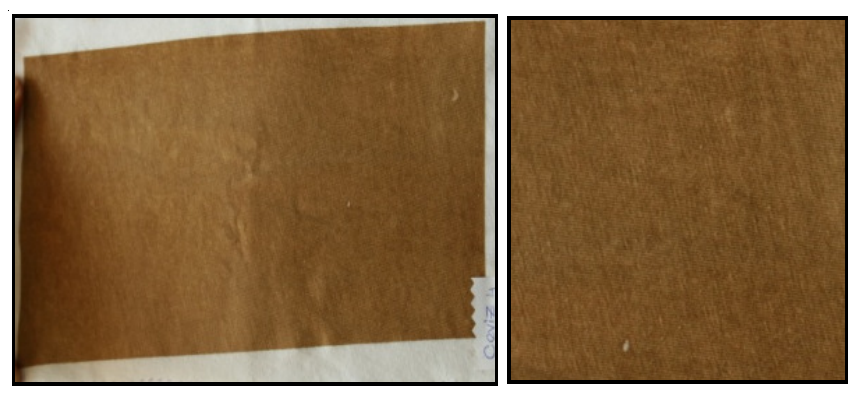

Walnut bark
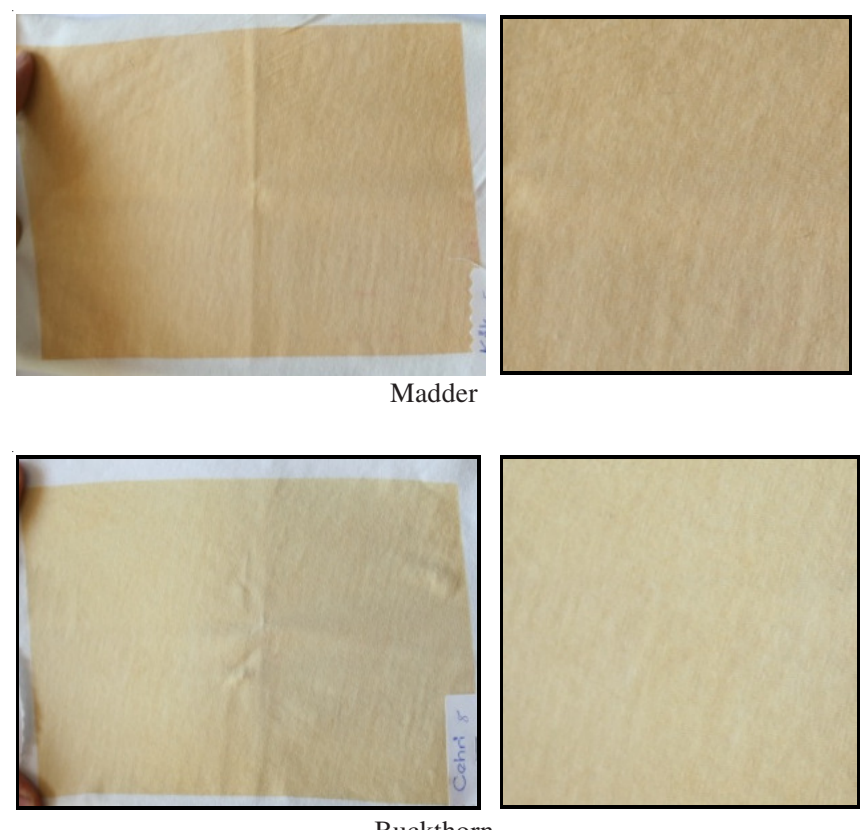

Fig. 3. Photographs of printed cotton fabrics

In madder based print the $\mathrm{L}^{*}$ was found 76.32 and the colour is found lighter then walnut bark based print. Addition to this the colour has shown lower reddish and a little higher yellowish with the values $\mathrm{a}^{*}=7.55\left(\mathrm{a}^{*}\right.$, negative values indicate green and positive values indicate red) and $b^{*}=29.45\left(b^{*}\right.$, negative values indicate blue and positive values indicate yellow) and a hue value of 75.62 (Table-2). In the light of these values we can say that for this kind of printings and for these recipes madder can be used for dark orange-light brown shades as seen from the Fig. 3 too.

For the buckthorn printing $\mathrm{L}^{*}$ value was measured as 82.19 (Table-2), which means the obtained colour is in particularly light shades. Another significant result is the $b^{*}$ value of the prints, it was found that the $b^{*}$ (28.94) was in yellow shade with a low shade of red $\left(a^{*}=2.18\right)($ Table-2). The hue angle is also confirming this argument. As seen the 85.69 of hue angle show the place of the colour in colour space as in yellow region. The colour efficiency of buckthorn printing was calculated as 2.76 . As a result it can be told that in cotton printing buckthorn can be used for yellow shades with good colour efficiencies and the Fig. 3 is backing this result.

In wool printing processes it was clearly told that the natural dye based printing can be managed like in cotton too. The colour efficiencies especially in indigo and buckthorn based prints are higher in wool than cotton. However cotton showed higher colour efficiencies in walnut bark and madder based prints (Fig. 2).

\begin{tabular}{lcccc}
\multicolumn{5}{c}{ TABLE-3 } \\
& $\mathrm{L}^{*} \mathrm{a}^{*} \mathrm{~b}^{*}$ VALUES OF PRINTED WOOL \\
\hline & Indigo & Walnut bark & Madder & Buckthorn \\
\hline $\mathrm{L}^{*}$ & 78.53 & 58.47 & 70.73 & 70.96 \\
$\mathrm{a}^{*}$ & -1.32 & 6.38 & 7.41 & 5.86 \\
$\mathrm{~b} *$ & 9.92 & 20.86 & 19.61 & 26.36 \\
Chroma $\left(\mathrm{C}^{*}\right)$ & 10.01 & 21.81 & 20.97 & 27 \\
Hue angle $\left(\mathrm{h}^{\text {o }}\right)$ & 97.57 & 73.01 & 69.3 & 77.46 \\
\hline
\end{tabular}


In walnut bark printing the $\mathrm{L}^{*}$ value was low as in cotton. This shows the low lightness of the colour. Addition to this, high $b^{*}$ value $\left(b^{*}\right.$, negative values indicate blue and positive values indicate yellow) and $\mathrm{a}^{*}$ value ( $\mathrm{a}^{*}$, negative values indicate green and positive values indicate red) indicated the colour in brown shade as predicted. This is also confirmed with the hue angle of 73.01 (Table-3). The photograph of the walnut bark based printed wool showed also the brown shade of the prints too (Fig. 4).
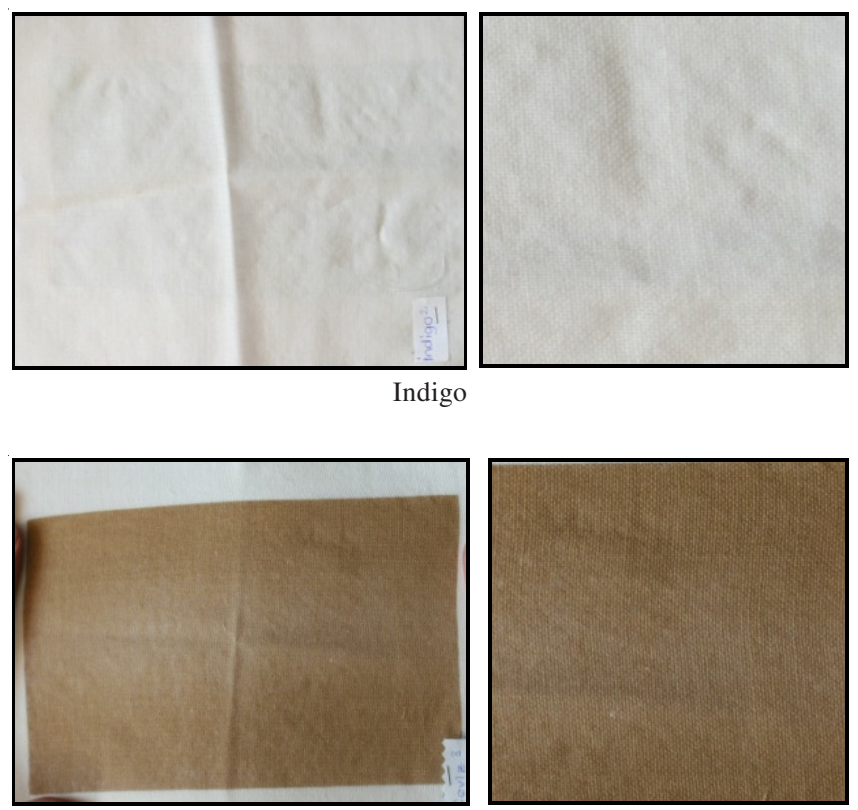

Walnut bark
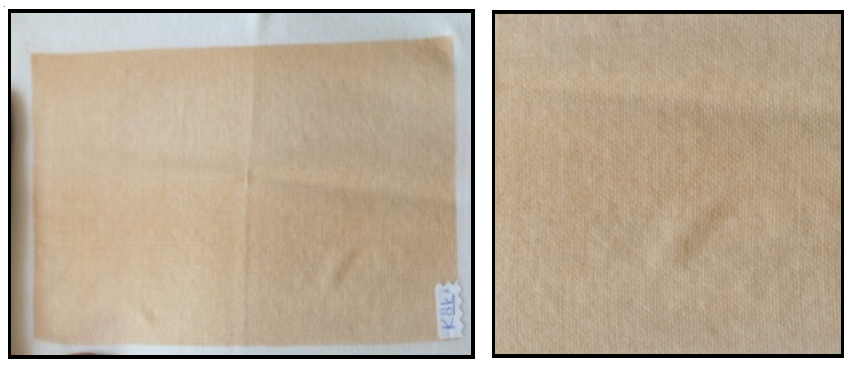

Madde
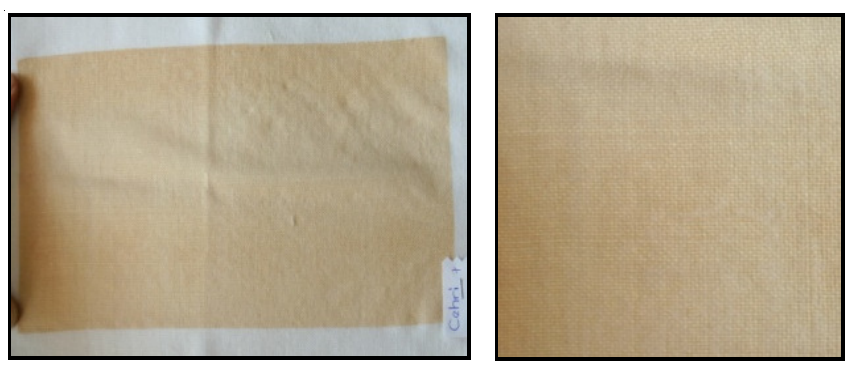

Buckthorn

Fig. 4. Photographs of printed wool fabrics

Like walnut bark based prints the madder based prints has in red-yellow region with a hue value of 69.03 and $L^{*}$ value of 70.73. As seen form Fig. 4 the colour of the madder based print can be expressed as light brown in red-pink shade. However in buckthorn based print, the colour has low a* value
(5.86) which means red shade of colour is low when compared with walnut bark and madder based prints. Moreover the $b^{*}$ value is high and 26.36 so the yellow shade can be said as dominant. In the light of these arguments and hue value of 77.46, buckthorn based print can be interpreted as yellow in orange shade (Fig. 4).

In indigo based printing an utterly different colour had been obtained as seen in Fig. 4. From the Fig. 4 it can be told that the colour is light blue as expected. The lightness of the colour has thought strongly related with the inadequate concentration of indigo in printing paste $\left(\mathrm{L}^{*}=78.53\right)$ and it is expected that if the extract will have the higher dyestuff concentration, the dark blues can be obtained. Table- 3 shows the colour values of indigo printed sample. It was observed that $a^{*}$ value is -1.32 whish means there is green shade and the $b^{*}$ value was 9.92 shows the yellow tendency of the colour.

Fastnesses of prints: The other important parameter for the evaluation of natural dyes use in printing processes is fastnesses of the prints. Owing to this, washing, rubbing, perspiration and light fastnesses of both wool and cotton printed fabrics were examined (Table-4).

In general, it is suggestive that the fastnesses are nearly same both in cotton and wool printed fabrics. For example when the washing fastness of printed samples investigated it was observed that the general fastnesses values are the same for cotton and wool fabrics. Beyond this, it was found that for all kind of dye, the staining value of wool (for printed wool fabric) and cotton (for printed cotton fabric) is 5 which mean no staining. This remarkable value is thought as related with the printing procedure. In the procedure we did not use mordant so when the dye which has low affinity, get in to the bath it did not want to go another undyed fabric. This is also confirmed by the alteration results. It shows in washing fastness procedure the dye is getting into bath but not to multi-fiber. Anyway, in general the washing fastness of fabrics in terms of staining was found 5 and 3 in terms of alteration except indigo based prints. Because in indigo based prints, the light shades were obtained and the dye used is low when compared with the other used natural dyes. As a result of this alteration is limited and found 4 for both cotton and wool.

Another, important fastness for pigment printing processes is rubbing fastness. Because of this, rubbing fastnesses of prints were evaluated too. It was found that in dry rubbing fastness for all natural dyes and both cotton and wool the value is 5 means excellent. In wet rubbing fastness, the values are generally 4-5, only in walnut bark based prints of cotton showed low fastness value of 3 . It is thought that, this is particularly related with the colour efficiencies and colour values of prints. It was found that the highest colour efficiency can be obtained with walnut bark based prints in cotton printing as mentioned above. The colour values and the photographs of the prints were also confirmed this (Fig. 2 and 3; Table-2). As a result of this, the wet rubbing fastness of walnut barks based printed cotton was limited.

Most of the natural dyes have poor to moderate light fastness. It is influenced by the chemical, physical state and concentration of dye, the nature of the fibers and the mordant type $^{16}$. Here in the study mordants were not used so there is no 
TABLE-4

FASTNESS PROPERTIES OF COTTON AND WOOL PRINTED FABRICS

\begin{tabular}{|c|c|c|c|c|c|c|c|c|c|c|}
\hline & & & & & & \multicolumn{4}{|c|}{ Perspiration } & \multirow{3}{*}{ Light } \\
\hline & & \multicolumn{2}{|c|}{ Washing } & \multicolumn{2}{|c|}{ Rubbing } & \multicolumn{2}{|c|}{ Acidic } & \multicolumn{2}{|c|}{ Alkaline } & \\
\hline & & Sta. $^{a}$ & Alt. $^{b}$ & Wet & Dry & Sta. ${ }^{a}$ & Alt. $^{b}$ & Sta. $^{a}$ & Alt. $^{b}$ & \\
\hline \multirow{4}{*}{$\begin{array}{l}\overline{8} \\
\overline{3}\end{array}$} & Madder & 5 & 3 & $4-5$ & 5 & 3 & 5 & $3-4$ & 5 & 3 \\
\hline & Buckthorn & 5 & 3 & 5 & 5 & 3 & 5 & 3 & 5 & 3 \\
\hline & Walnut Bark & 5 & 3 & $4-5$ & 5 & 4 & 5 & $4-5$ & 5 & 6 \\
\hline & Indigo & 5 & 4 & $4-5$ & 5 & $4-5$ & 5 & 5 & 5 & 6 \\
\hline \multirow{4}{*}{ ن̃ } & Madder & 5 & $2-3$ & $4-5$ & 5 & 3 & 5 & 3 & 5 & 3 \\
\hline & Buckthorn & 5 & 3 & $4-5$ & 5 & 3 & 5 & 3 & 5 & 4 \\
\hline & Walnut Bark & 5 & 3 & 3 & 5 & 4 & 5 & 4 & 5 & 6 \\
\hline & Indigo & 5 & 4 & 5 & 5 & $4-5$ & 5 & 5 & 5 & 6 \\
\hline
\end{tabular}

a. Staining on wool (for wool fabrics) or cotton (for cotton fabrics); b. Alteration

relation with mordant type with the obtained light fastnesses. On the other hand the type of fiber can be important as mentioned in terms of light fastnesses, however it was observed that nearly same results in wool and cotton, for all used natural dyes were obtained. As a result it can be mentioned that the chemical structure of the dyes for this type of printings were more characteristic in terms of the light fastnesses obtained.

It was observed that good light fastnesses can be obtained for the walnut bark and indigo based natural dyes. Six point was reached for both wool and cotton fabric printing with walnut bark and indigo. However, for madder printing poor fastnesses were obtained in both cotton and wool. Buckthorn has also shown nearly same tendency like madder but different fastnesses according to the fiber type. It was observed that the light fastness for wool was poor (3 point) but for cotton was moderate ( 4 point) in buckthorn prints.

\section{Conclusion}

Today an increasing interest on the use of natural dyes has been come out. This interest on natural dyes is somewhat related with the demand on the use of natural substances instead of synthetic substances. However natural dyes have also some drawbacks; during the process generally a mordant which is usually a salt of metal ions are needed. In addition to this, its fastnesses especially light fastnesses are not very well but still the natural dyes are preferred in special goods and carpets.

Use of natural dyes in printing processes is not common. As known the earliest colourants used in printing were mineral pigments, but today there is a wide range of excellent organic pigments and of reliable pigment binders ${ }^{17}$. But this study shows that how easy to use natural dyes in pigment printing process. For this, the natural dyes were used in pigment printing without any mordants with binder. In the study it was suggested that the natural dyes can be used in printing processes. In pigment printing with the use of dye extracts as a dyestuff, printing process can be managed with sufficient fastnesses, different colours and shades. It is thought that with the use of different natural sources to obtain natural dyes, different colours will be observed. It is also expected that in the extraction period if the extract can be made in more concentrated from the colours will be obtained in darker shades too. Finally, it is presumed that the demand on the consumption of natural based goods in all industrial applications will trigger the use of natural dyes in printing processes too and we hope that this study will be useful in the further researches.

\section{REFERENCES}

1. M. Rekabya, A.A. Salemb and S.H. Nassara, J. Text. Inst., 100, 486 (2009).

2. A.K. Samanta and A. Konar, in ed.: E.P.A. Kumbasar, Dyeing of Textiles with Natural Dyes, Natural dyes, In Tech, Croatia, pp. 29-56 (2011).

3. A.K. Samanta and P. Agarwal, Indian J. Fibers Text. Res., 34, 384 (2009).

4. R. Bhuyan and C.N. Saikia, Bioresour. Technol., 96, 363 (2005).

5. H.T. Deo and B.K. Desai, Colour. Technol., 115, 224 (1999).

6. F.A. Nagia and R.S.R. El-Mohamedy, Dyes Pigments, 75, 550 (2007).

7. R. Agarwal, N. Prtuhi and S.J.S. Singh, Nat. Prod. Rad., 6, 306 (2007).

8. M.M. El-Molla and R. Schneider, Dyes Pigments, 71, 130 (2006).

9. H. Gutjahr and R.R. Koch, in ed.: L.W.C. Miles, Direct Print Colouration, Textile Printing (Revised Second Edition), Society of Dyers and Colourists, Bradford West Yorkshire, England, pp. 140-153 (2003).

10. R.M. El-Shishtawy and S.H. Nassar, Colour. Technol., 118, 115 (2002).

11. N. Çaglarirmak, Nahrung/Food, 47, 28 (2003).

12. A. Önal, Turkish J. Chem., 20, 204 (1996).

13. O. Deveoglu, R. Karadag and T. Yurdun, Jordan J. Chem., 4, 377 (2009).

14. K.G. Gilbert and D.T. Cooke, Plant Growth Regul., 34, 57 (2001).

15. A.C. Dweck, Int. J. Cosm. Sci., 24, 287 (2002).

16. D. Cristea and G. Vilarem, Dyes Pigments, 70, 238 (2006).

17. L.W.C. Miles, Traditional Methods, Textile Printing (Revised Second Edition), Society of Dyers and Colourists, Bradford West Yorkshire, England, pp. 8 (2003). 